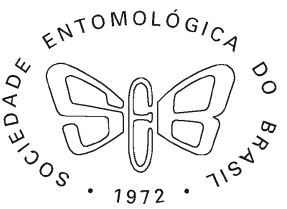

\title{
Insect Pollination, More than Plant Nutrition, Determines Yield Quantity and Quality in Apple and Pear
}

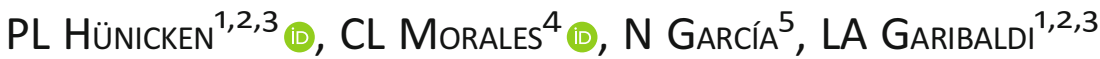 \\ ${ }^{1}$ Univ Nacional de Río Negro, Instituto de Investigaciones en Recursos Naturales, Agroecología y Desarrollo Rural, San Carlos de Bariloche, Río \\ Negro, Argentina \\ ${ }^{2}$ Consejo Nacional de Investigaciones Científicas y Técnicas, Instituto de Investigaciones en Recursos Naturales, Agroecología y Desarrollo \\ Rural, San Carlos de Bariloche, Río Negro, Argentina \\ ${ }^{3}$ Instituto de Investigaciones en Recursos Naturales, Agroecología y Desarrollo Rural, Sede Andina, UNRN, Viedma, Argentina \\ ${ }^{4}$ Instituto Biodiversidad y Medio Ambiente (INIBIOMA), Univ Nacional del Comahue-CONICET, Grupo de Ecología de la Polinización, San Carlos \\ de Bariloche, Río Negro, Argentina \\ ${ }^{5}$ Centro PYME, Agencia de Desarrollo Económico del Neuquén, Neuquén, Argentina
}

\section{Keywords}

Agricultural production, interaction, pollinators, Apis mellifera

\section{Correspondence}

PL Hünicken, Univ Nacional de Río Negro, Instituto de Investigaciones en Recursos Naturales, Agroecología y Desarrollo Rural, San Carlos de Bariloche, Río Negro, Argentina; pablohunicken@gmail.com

Edited by Claudia Inês Silva - UNESP

Received 29 July 2019 and accepted 30 January 2020

(C) Sociedade Entomológica do Brasil 2020

\begin{abstract}
Agricultural yield is the result of multiple factors and ecological processes (e.g., pollination, fertilization, pest control). Understanding how the different factors interact is fundamental to designing management practices aimed to increase these yields, which are environmental friendly and sustainable over time. In this study, we focus on insect pollination and plant nutrition status, since they are two key factors that influence crop yield. The study was carried out in Northwest Patagonia Argentina, which is an area of intensive production of pears and apples of global importance, during the harvest seasons 2018 and 2019. The plant nutrition was estimated from leaf chlorophyll content. Biotic pollination benefits were evaluated by comparing fruit quantity (fruit to flower ratio) and quality (weight, size, and sugar concentration) from approximately 25 flowers exposed to pollinators and 25 flowers excluded to them per tree (a total of 160 apple trees and 130 pear trees). In addition, we estimated the visitation rate of pollinators to flowers and related it to fruit quality in apple. Despite different floral characteristics, we found in both crops a positive effect of insect pollination in both the quantity and the quality of the fruits. Interestingly, the nutrition of the trees, although variable, did not affect either the quantity or the quality of the fruits. Despite the weak effect of nutrition, we found no interaction between pollination and plant nutrition (i.e., additive effects). These results highlight the importance of agricultural practices that promote pollinators on farms.
\end{abstract}

\section{Introduction}

In the past century, agricultural yields (tn. $\mathrm{ha}^{-1}$ ) were improved by increasing inputs of fertilizers, pesticides, and genetic modifications (i.e., conventional intensification). These practices entail drastic consequences to the environment and biodiversity (e.g., habitat degradation and biodiversity loss, Matson et al 1997, Tilman 1999). Moreover, conventional agriculture achieves good results in the short term but proved ineffective in maintaining long-term yield, because it harm the ecosystem processes that can sustain the production (Matson et al 1997, Brummer 1998). Reaching a sustainable, environmentalfriendly agricultural production is therefore a major challenge of this time. 
Crop yield is the result of multiple factors of agricultural production that act simultaneously, some of them are natural properties derived from biophysical and/or ecological processes (e.g., pollination, soil fertility) and others are agricultural inputs (e.g., fertilization, irrigation). Despite that, research usually focuses only on one or two factors at a time and compares contrasting levels of them, so non-linear trends, which are expected to be found in yield responses, cannot be detected (Ruel \& Ayres 1999). For example, a recent review found nine studies (only three in perennial crops) that evaluate the interaction between pollination and soil fertility/fertilization (Garibaldi et al 2018). These studies are not only scarce, but they also show opposite results: no interaction (Groeneveld et al 2010, Boreux et al 2013, Bartomeus et al 2015, Klein et al 2015, Gils et al 2016), benefits of pollination maximized at low or intermediate levels of nutrients (Marini et al 2015, Tamburini et al 2017), and benefits of pollination maximized at high levels of nutrients (Tamburini et al 2016), highlighting the need of more studies in this field.

Pollinators are determinant to agricultural production, since $70 \%$ of the globally most important crop species benefit from animal pollination (Klein et al 2007). Alarmingly, both wild and managed pollinators are threatened by conventional intensification of agriculture, compromising pollination (Potts et al 2010a, b, González-Varo et al 2013, Aizen et al 2019). This is of particular concern, because global agriculture is increasingly dependent on animal pollination (Aizen \& Harder 2009, Aizen et al 2019). Understanding the degree in which pollination and other main factors affect crop yield and how these factors interact is key to develop management practices that enhance crop yield minimizing the impact on the biodiversity and the environment.

In this work, we evaluated the interaction between pollination and plant nutrition on the yield components such as fruit quantity and quality of two crops: apple (Malus domestica) and pear (Pyrus communis). We performed a manipulative and observational test to answer the following questions: (1) Which factor (i.e., pollination or plant nutrition) is more important to determine yield? (2) Do pollination and plant nutrition interact? If so, in which way?

\section{Material and Methods}

\section{Study system}

This study was carried out during austral seasons 2017-2018 and 2018-2019 (hereafter 2018 and 2019, respectively), since flowering in September to harvest in March. The study area is an irrigation valley immerse in the arid steppe of Argentine Patagonia, known as the "Alto Valle de Río Negro." This region concentrates 85 and $75 \%$ of the Argentine apple and pear production respectively (Geslin et al 2017). Typically, the farms present conventional management, with high use of pesticides and fertilizers. The selected farms had the same management practices, so we do not expect pesticides or fertilizers to be responsible for differences between farms. Watering is usually achieved by completely flooding the plot, and tillage is a recurrent practice. Because of the low abundance of wild pollinators, perhaps due to the high use of pesticides, installation of honeybee (Apis mellifera (Linnaeus)) hives is a common practice.

The farms selected are near to the locality of "San Patricio del Chañar", Neuquén province (approx. $38^{\circ} 37^{\prime} \mathrm{S}, 68^{\circ} 18^{\prime} \mathrm{W}$, Fig 1). We carried out our measurements in ten trees per farm, in eight apple farms each season, and in seven and six pear farms in the seasons 2018 and 2019, respectively. All farms were separated from each other by at least $1.5 \mathrm{~km}$. The crop varieties chosen were Red Delicious, for apple, and Packham's Triumph, for pear, both representatives of the varieties grown in this region. Both crops have perfect flowers (i.e., female and male organs in the same flower), are self-incompatible, and depend on cross-pollination to set fruit (Jackson 2003, Maccagnani et al 2003, Ramírez \& Davenport 2013). The amount and sugar concentration of nectar differ: apple flowers produce more nectar and with higher sugar concentration than pear (Farkas \& Orosz-Kovács 2003, Jackson 2003, Maccagnani et al 2007, Díaz et al 2013).

\section{Pollination treatment and visitation rate}

To evaluate the effect of insect pollination, we excluded from flower visitors $20.6 \pm 0.5$ (mean \pm SD) flowers per tree (exclusion treatment), and we marked $27.3 \pm 0.5$ flowers freely exposed to them (open treatment). Exclusion was performed by covering 1 or 2 inflorescences with tulle bags (mesh size $2 \mathrm{~mm}$ ). In total, we followed 10,376 individual apple flowers and 9313 pear flowers. During blossom, we did visit censuses in all the focal trees (range $=2-5$ and $3-6$ census per pear and apple tree respectively), between 9:00 am to 6:00 pm and when the temperature exceeded $15^{\circ} \mathrm{C}$. Depending on the time of the day, we randomly selected more or less inflorescences (e.g., in the midday, we cover 3 or 4 , while in the morning, we cover approx. 10 inflorescences to avoid false zeros), we counted the number of flowers and recorded the number of flowers visited by each floral visitor during a 10-min timeframe in each tree. Each orchard was sampled on different days and at different times of the day, to cover the temporal variation in the visitation rate. We categorized the visitors in the following functional groups: A. mellifera, bumblebees (Bombus sp.), hoverflies (Syrphidae), and other species. A mean of $43.2 \pm 0.8$ and $33.7 \pm 0.5$ flowers per tree was observed in each census on apple and pear, respectively. 


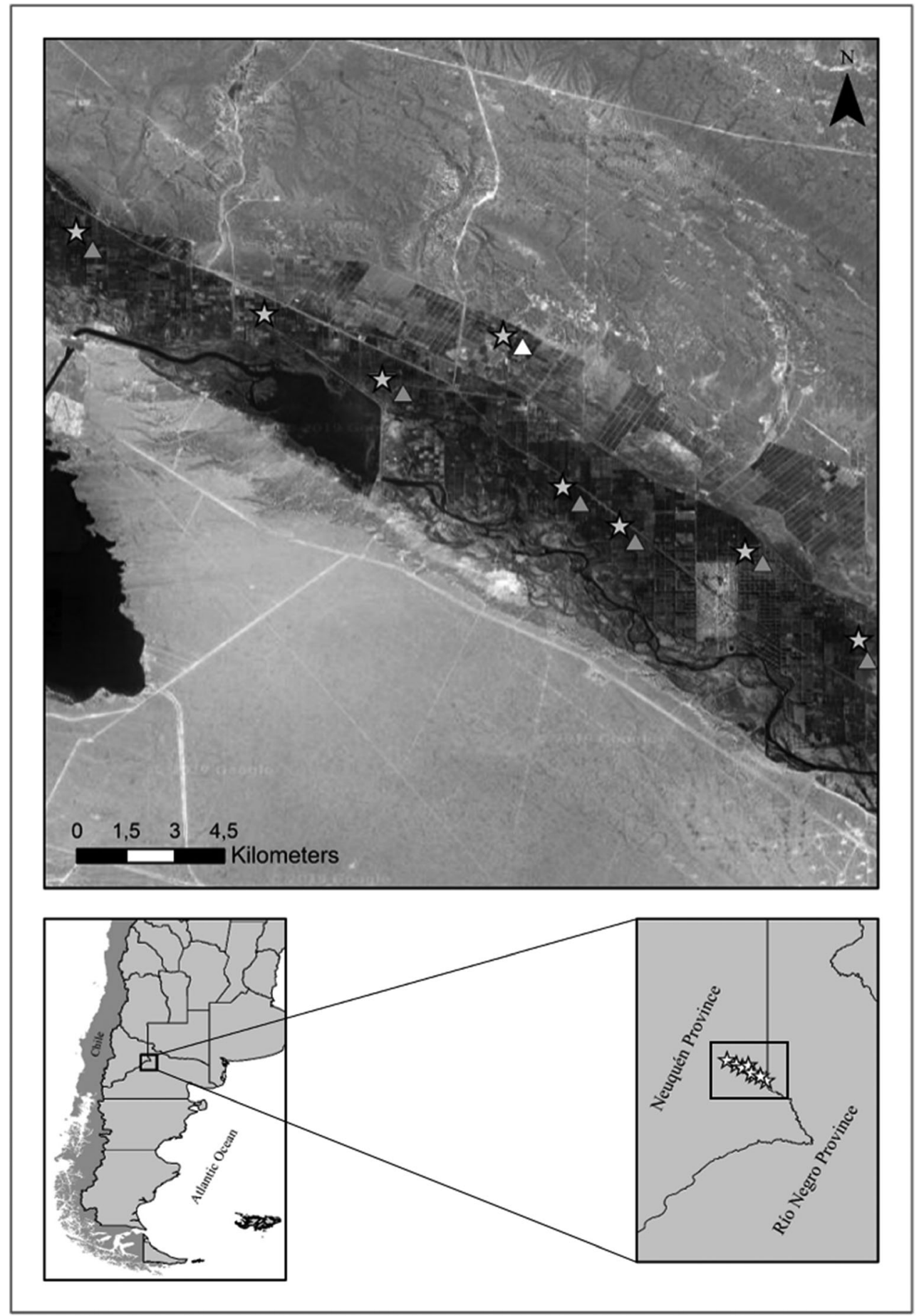

Fig 1 Study area. Apple farms are pointed with stars. Pear farms are pointed with triangles. White triangle represents the pear farm surveyed in season 2018 but not in 2019. Map drawn by Msc. Fernanda Santibañez with ArcGis.

\section{Plant nutrition}

To evaluate the nutrition of the trees, we estimated the chlorophyll content on 30 leaves from the midportion of each tree with a SPAD 502-PLUS chlorophyll meter. This instrument provides information on plant vigor and chlorophyll content by measuring the absorbance of two wavelengths (approx. 650 and $940 \mathrm{~nm}$ ). The value given by the SPAD is an arbitrary unit that ranges from o to (theoretical) infinite; the greater the value, the higher the plant vigor is. SPAD units are a good indicator of plant nutrition, and several studies provide regression equations that allow us to convert the SPAD units to nitrogen concentration (Neilsen et al 1995, Porro et al 2001, Neto et al 2011). 
Fruit quantity and quality

\section{Early and final fruit set}

In December of each year, ca. 12 weeks after the end of blooming and before the period of natural thinning for pears and chemically induced thinning for apples, we counted the number of fruit set per flowers in branches assigned to our open and exclusion treatments, which was defined as the early fruit set. In February, a few days before harvest, we counted the fruits again in order to calculate the final fruit set.

\section{Fruit quality}

In February, when the harvest has just been authorized, we collected all the fruits of our treatments to assess the fruit quality. We measured fruit weight, size (height and diameter), and sugar concentration. Weight was measured using a digital balance with $0.1 \mathrm{~g}$ of precision. Height and diameter were measured using a digital caliper with $0.1 \mathrm{~mm}$ of precision. Sugar concentration (in BRIX \%) was measured using a portable refractometer with $0.2 \%$ BRIX of precision.

\section{Statistical analyses}

We estimated linear mixed-effects models (LMM) with package "Ime4" of R program (Bates et al 2015, R Core Team 2015). We used the variables of fruit quality (weight, height, diameter, and sugar) and quantity (earlier and final fruit set) as response variables, with a Gaussian error structure. The assumptions of the models were checked by means of graphics (QQ-plot, predicts vs. residuals, etc.) and analytic inference (Kolmogorov-Smirnov test). We performed two sets of models. In the first one, pollination treatment (factor with two levels: "open" and "exclusion"), chlorophyll content (quantitative, in SPAD units), and season (factor with two levels: "2018" and "2019") and their interactions were modeled as fixed effects. In the second set of models, we only used the data from the open treatment, so visitation rate (quantitative, number of visit per flower, $10 \mathrm{~min}^{-1}$ ), chlorophyll content (quantitative, in SPAD units) and season (factor with two levels: "2018" and "2019") and their interactions were modeled as fixed effects. In all of them, "farm" and "tree" nested within "farm" were modeled as random effects. We selected the minimum adequate model by the lowest AIC (Akaike information criterion) value using the function dredge of package MuMin (Burnham et al 2011, Barton 2018). We calculated the relative importance value for each predictor variable with the importance function in the package MuMin, which sums the "Akaike weights" over all the models that include the predictor variable. Spearman correlations were performed to explore the correlation between variables.

\section{Results}

\section{Visitation rate}

We recorded a total of 10,371 visits to apple and pear flowers in 1048 pollinator censuses. Apis mellifera accounted for the vast majority (99.7\%) of the visits in both apple and pear crops. Visitation rate (visits per flower. $10 \mathrm{~min}^{-1}$ ) was one order of magnitude higher in apple trees (mean \pm SD, 0.32 $\pm 0.02)$ than that in pear trees (0.062 \pm 0.007$)$.

\section{Plant nutrition}

Apple trees had a mean ( \pm SD) SPAD value of $41.5 \pm 0.3$ (range $=29.9-52.1$ ), representing a mean leaf nitrogen concentration of $2.45 \%$ of dry weight (range $=2.14-2.74$ ). Pear trees had a mean $( \pm$ SD) SPAD value of $42.0 \pm 0.1$ (range $=$ 33.4-46.0), which also represented a mean leaf nitrogen concentration of $2.45 \%$ of dry weight (range $=2.02-2.64$ ). For both crops, the nutritional status of the trees represented a gradient within the recommended nitrogen concentration (Neilsen et al 2003, Hoying et al 2004).

\section{Exclusion treatment, plant nutrition, and crop yield}

Exclusion treatment reduced early and final fruit set almost totally in apple trees, compared with the open treatment. In the case of pear trees, early fruit set had no differences between treatments, but the final fruit set of the exclusion treatment was reduced by half compared with the open treatment (see Fig 2 and Table $\mathrm{S} 1$ in the supplementary material) in the supplementary material. Although the SPAD level remains in the minimum models, its effect was irrelevant (estimated coefficients and the relative importance of variables are detailed in Tables S1 and S2 in the supplementary material) and did not interact with pollination treatment.

Given the low number of apples harvested from the exclusion treatment, we could not assess its effect on quality. In the case of pears, exclusion worsened all indicators of fruit quality, compared with open (in percent \pm SD): $10 \pm 3 \%$ of weight, $5 \pm 2 \%$ of diameter and height, $2 \pm 1 \%$ of sugar content. Fig 3 shows the response of weight to pollination treatment, which is highly correlated with the rest of the quality variables (see Table S3 in the supplementary material, Spearman correlations). No substantial effect of the SPAD level or interaction was found.

\section{Visitation rate, plant nutrition, and crop yield}

Early and final fruit set of both crops was not related to the visitation rate of pollinators. However, all indicators of quality of apples increased per unit of visitation rate (in percent \pm SD): $24 \pm 6 \%$ of weight, $14 \pm 3 \%$ of diameter, $12 \pm 3 \%$ of 

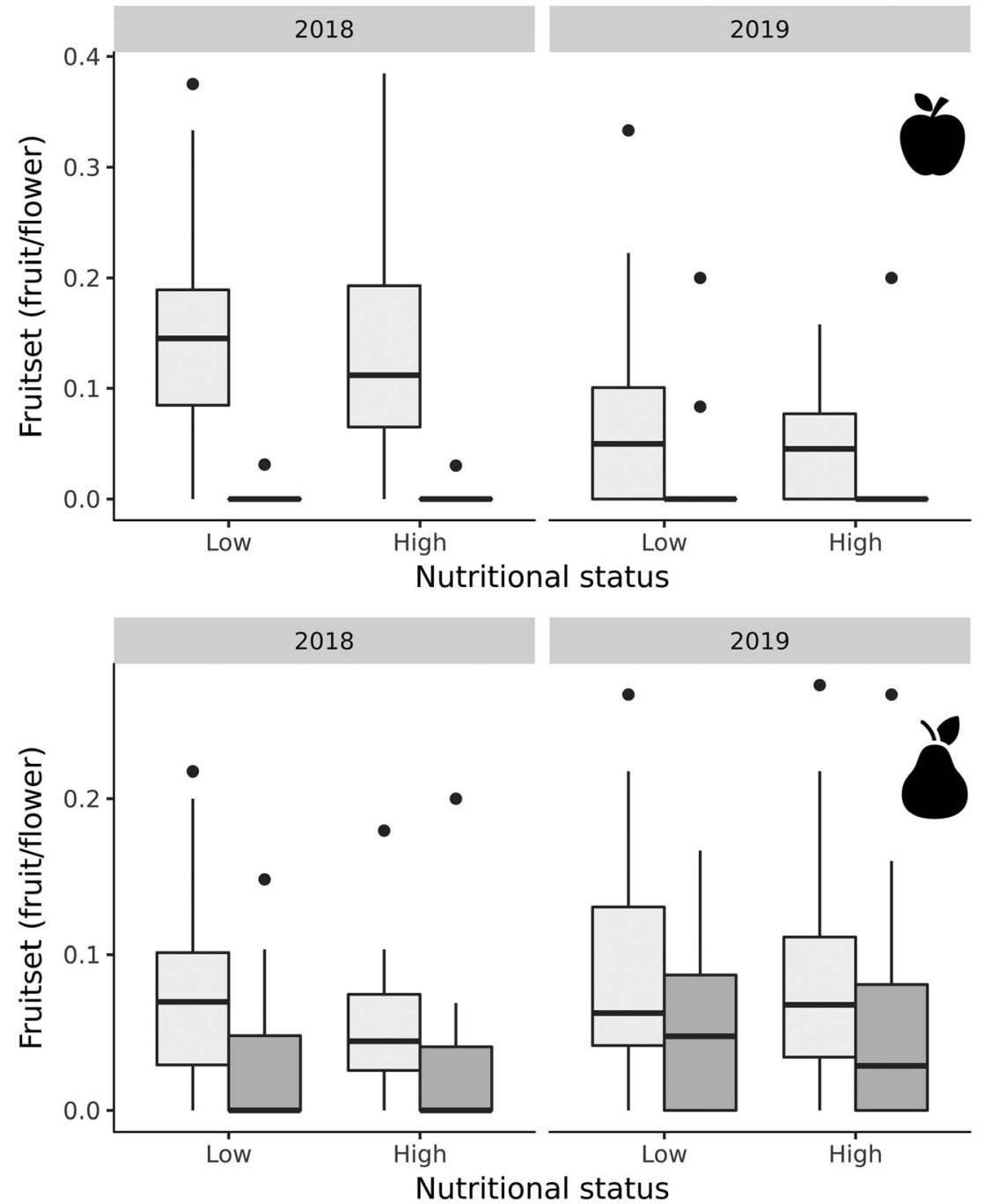

Fig 2 Final fruit set of open (light grey boxes) and exclusion (grey boxes) treatments vs. nutritional status. Above: apples; below: pears. Although SPAD value is quantitative, for better visualization, the values of each tree were standardized according to the median of the farm and categorized the negative values as "low" (i.e., below the median) and the positive ones as "high" (i.e., above the median). Boxes show the inter-quartile range (IQR); horizontal line represents the median; whiskers show the range of $1.5^{*} \mathrm{IQR}$. Figure build with $\mathrm{R}$.

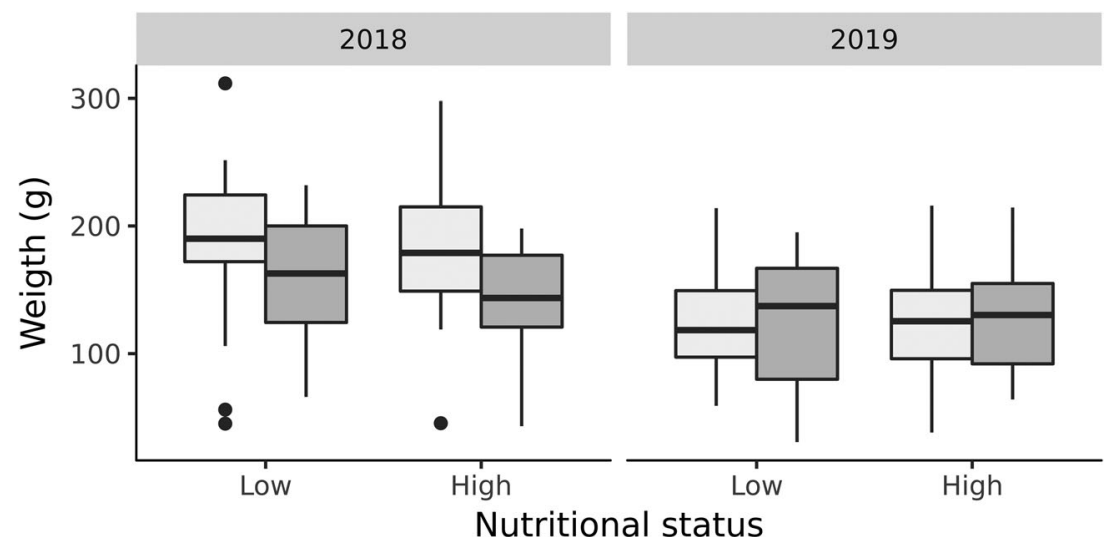

Fig 3 Weight (g) of pears from open (light grey boxes) and exclusion (grey boxes) treatment vs. nutritional status. Although SPAD value is quantitative, for better visualization, the values of each tree were standardized according to the median of the farm and categorized the negative values as "low" (i.e., below the median) and the positive ones as "high" (i.e., above the median). Boxes show the inter-quartile range (IQR); horizontal line represent the median; whiskers show the range of $1.5^{*}$ IQR. Figure build with R. 
height, and $5 \pm 4 \%$ of sugar (Fig 4 , and Tables S 4 and S5 in the supplementary material). For the pears, visitation rate did not remain in the minimum model, possibly due to its low magnitude and variance, wich did not allow us to detect a possible effect (see above). Again, no substantial effect of the SPAD level or interaction was found.

\section{Discussion}

The analysis of two productive seasons in pear and apple orchards shows the clear benefits to yield of insect pollination in both crops. Interestingly, plant nutrition did not affect in a notorious way both the quantity and quality of yield. Because of this, our results support the hypothesis of the additive effect of nutrition and pollination. Similar results were obtained by Klein et al (2015) in almond crop in California, suggesting that perennial crops are more resilient to variation in nutrition levels, perhaps due to the accumulation of nutrients, so in years with lower nutrient uptake the trees would prioritize fruit development over vegetative performance. This is important in view of the yield stability, which will be more reliant on the maintenance of the pollination process than to the nutrient supply.

A major component of yield is fruit quantity. We found a notorious reduction in the final fruit set of flowers isolated from pollinators in pear $(48.9 \%$ less compared with open treatment) and apple (97.0\% less compared with open treatment). Interestingly, the final fruit set was not related to the visitation rate, unlike previous studies in this system (Geslin et al 2017). For apple trees, this result suggests that flowers are receiving an optimum value of visits as reported by Vicens \& Bosch (2000), because the first decile of visitation rate was 82 visits per hour per 100 flowers. These overwhelming results confirm the improvement in yield quantity given by insect pollination.
Quality (i.e., height, diameter, and weight) of fruits can be as important as the quantity. Small fruit has lower market value, so producer's income is strongly linked to fruit quality (Garratt et al 2014). We have found in both apple and pear that insect pollination increases the quality, demonstrating the benefits of pollinators for producers. Fruit weight showed the most notorious response to pollinators. In pear trees, flowers exposed to pollinators produced fruits on average $5 \%$ heavier than flowers not exposed, while in apple trees, fruit weight incremented a $24 \%$ per visitation rate unit. These results revalue insect pollination since fruit quality is not only a key component of crop yield but also of farmers' profits (Geslin et al 2017).

An important point to highlight is that chemical thinning is a regular practice in apple crop. This practice aims to homogenize the quality of the fruits. For this reason, many land managers and agronomists do not conceive pollination as an important factor to consider in agricultural management. Here, we demonstrate that the positive effect of flower visitation by pollinators on fruit quality persists even after chemical thinning. This is probably due to an improvement in the quality of pollen that reaches the flowers, and provides arguments to value pollinators (Aizen \& Harder 2007).

In our system, we found strong differences between crops in insect visitation. Because in most orchards, apple and pear tree rows are planted very close to each other, and managed honeybees accounted for almost all flower visits, we do not expect that landscape context or location of the hives to be responsible for this difference in pollinator supply (Free \& Williams 1974). Moreover, although in this region pear starts blooming a few days earlier, both crops overlap in most of their blooming time (Díaz et al 2013, Geslin et al 2017). Therefore, phenological differences, which may reflect different weather conditions in this cold climate, do not seem to be enough to explain one order of magnitude of differences in visitation. Genetic of the hives could be a reason for the

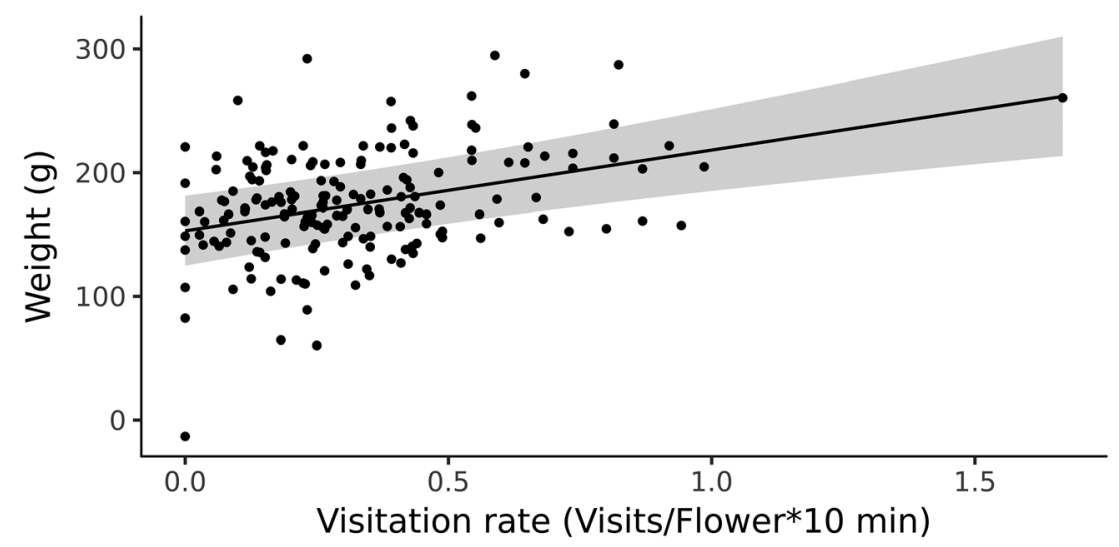

Fig 4 Conditional plot of weight (g) of apple fruit vs. visitation rate (visits per flower. $10 \mathrm{~min}^{-1}$ ). Grey band represents confidence interval of the prediction line. The removal of the outlier point on the right extreme does not affect the output of the model neither the conclusion. Figure build with R. 
preference of apple flowers over the pear flowers (Dag et al 2005). Also, the type, quantity, and quality of floral rewards may explain a higher appeal of bees to apple than to pear flowers. A previous study in the same region showed that nectar volume produced by apple flowers is four times larger and nectar sugar concentration is twice higher than those in pear flowers (Díaz et al 2013 supp. Mat). Moreover, they showed that nectar foragers preferred apple over pear flowers, while pollen foragers showed the opposite preference (Díaz et al 2013). Thus, our results suggest a higher demand of nectar than pollen from the beehives of our system.

Although we covered a broad spectrum of the leaf dry nitrogen concentration, in a gradient within the normal recommended range for these crops (Dris et al 1999, Dar et al 2015), we find a low effect of this in both crops' yield. One possible cause could be that the SPAD value is not related to one key nutrient, besides nitrogen, for fruit development. Porro et al (2001) found a positive relationship between the SPAD value and leaves' nitrogen, magnesium, and calcium concentration and a negative relationship for potassium and boron concentration, while phosphorus (an important macronutrient) was not measured. Another possibility could be that perennial crops have resilience to stress. In almond, Esparza et al (2001) found a negative effect on yield after 3 years of water stress, while Klein et al (2015) found no effect of nutrition or water stress on yield in one harvest season. Our results suggest that yield in both crops is more influenced by insect pollination than nutrient supply.

In conclusion, we have found that insect pollination, which is usually underestimated as a critical process underlying crop yield, can be more (or at least equally important) than other factors such as plant nutrition. Even more, this effect is consistent in two crops with different floral rewards to pollinators, degrees of auto compatibility, and pollinator dependence (Free 1993, Klein et al 2007). The fact that pollination has overwhelming effect on yield quantity and quality highlights the importance of management practices that promotes pollinators in farms.

Acknowledgments We thank owners and managers of the farms for opening their doors. We also want to thank Néstor Pérez-Méndez who made valuable comments on the previous version of the manuscript and to Adrián González Chaves, Maria Ramos, Dulce Gómez Carella, Tatiana Machado de Souza, Eduardo Moreira, Rafaela Santos, Alberto Girotto, Joana Ferreira, and Grecia de Groot who assisted in the field.

Authors' Contributions LAG and PLH conceived the idea and designed the study. PLH and NG collected the data. PLH analyzed the data with substantial inputs from LAG. PLH, LAG, and CLM led the writing of the manuscript. All authors gave final approval for publication.

Electronic supplementary material The online version of this article (https://doi.org/10.1007/s13744-020-00763-0) contains supplementary material, which is available to authorized users.
Funding Information This work was financially supported by the Agencia Nacional de Promoción Científica y Tecnológica (PICT 20152333).

\section{References}

Aizen MA, Aguiar S, Biesmeijer JC, Garibaldi LA, Inouye DW, Jung C et al (2019) Global agricultural productivity is threatened by increasing pollinator dependence without a parallel increase in crop diversification. Glob Chang Biol. https://doi.org/10.1111/gcb.14736

Aizen MA, Harder LD (2007) Expanding the limits of the pollen-limitation concept: effects of pollen quantity and quality. Ecology 88(2):271-281

Aizen MA, Harder LD (2009) The global stock of domesticated honey bees is growing slower than agricultural demand for pollination. Curr Biol 19(11):915-918

Bartomeus I, Gagic V, Bommarco R (2015) Pollinators, pests and soil properties interactively shape oilseed rape yield. Basic Appl Ecol 16(8):737-745

Barton K (2018). MuMIn: multi-model inference. $\mathrm{R}$ package version 1.40.4. https://CRAN.R-project.org/package=MuMIn

Bates D, Maechler M, Bolker B, Walker S (2015) Fitting linear mixedeffects models using Ime4. J Stat Softw 67(1):1-48. https://doi.org/ 10.18637/jss.v067.io1

Boreux V, Kushalappa CG, Vaast P, Ghazoul J (2013) Interactive effects among ecosystem services and management practices on crop production: pollination in coffee agroforestry systems. Proc Natl Acad Sci 110(21):8387-8392

Brummer EC (1998) Diversity, stability, and sustainable American agriculture. Agron J 90(1):1-2

Burnham KP, Anderson DR, Huyvaert KP (2011) AIC model selection and multimodel inference in behavioral ecology: some background, observations, and comparisons. Behav Ecol Sociobiol. https://doi.org/10. 1007/s00265-010-1029-6

Dag A, Stern RA, Shafir S (2005) Honey bee (Apismellifera) strains differ in apple (Malus domestica) pollen foraging preference. J Apic Res 44(1):15-20

Dar MA, Wani JA, Raina SK, Bhat MY, Malik MA (2015) Relationship of leaf nutrient content with fruit yield and quality of pear. J Environ Biol 36(3):649

Díaz PC, Arenas A, Fernández VM, Susic Martin C, Basilio AM, Farina WM (2013) Honeybee cognitive ecology in a fluctuating agricultural setting of apple and pear trees. Behav Ecol 24(5):1058-1067

Dris R, Niskanen R, Fallahi E (1999) Relationships between leaf and fruit minerals and fruit quality attributes of apples grown under northern conditions. J Plant Nutr 22(12):1839-1851

Esparza G, DeJong TM, Weinbaum SA, \& Klein I (2001). Effects of irrigation deprivation during the harvest period on yield determinants in mature almond trees. Tree Physiology, 21(14), 1073-1079. https://doi. org/10.1093/treephys/21.14.1073

Farkas A, Orosz-Kovács Z (2003) Nectar secretion dynamics of Hungarian local pear cultivars. Plant Syst Evol 238(1-4):57-67

Free JB (1993). Insect pollination of crops (No. Ed. 2). Academic press, $p$ 684

Free JB, Williams IH (1974) Influence of the location of honeybee colonies on their choice of pollen sources. J Appl Ecol 11(3):925. https:// doi.org/10.2307/2401754

Garibaldi LA, Andersson GK, Requier F, Fijen TP, Hipólito J, Kleijn D, ..., \& Rollin O (2018). Complementarity and synergisms among ecosystem services supporting crop yield. Global Food Security, 17, 38-47

Garratt MP, Breeze TD, Jenner N, Polce C, Biesmeijer JC, Potts SG (2014) Avoiding a bad apple: insect pollination enhances fruit quality and economic value. Agric Ecosyst Environ 184:34-40 
Geslin B, Aizen MA, Garcia N, Pereira AJ, Vaissière BE, Garibaldi LA (2017) The impact of honey bee colony quality on crop yield and farmers' profit in apples and pears. Agric Ecosyst Environ 248:153-161

Gils S, Putten WH, Kleijn D (2016) Can above-ground ecosystem services compensate for reduced fertilizer input and soil organic matter in annual crops? J Appl Ecol 53(4):1186-1194

González-Varo JP, Biesmeijer JC, Bommarco R, Potts SG, Schweiger O, Smith HG, Steffan-Dewenter I, Szentgyörgyi H, Woyciechowski M, Vilà $M$ (2013) Combined effects of global change pressures on animalmediated pollination. Trends Ecol Evol 28(9):524-530

Groeneveld JH, Tscharntke T, Moser G, Clough Y (2010) Experimental evidence for stronger cacao yield limitation by pollination than by plant resources. Perspect Plant Ecol Evol Syst 12(3):183-191

Hoying S, Fargione M, lungerman K (2004) Diagnosing apple tree nutritional status: leaf analysis interpretation and deficiency symptoms. $\mathrm{N}$ YFruit Q 12(11):16-19

Jackson JE (2003) The biology of apples and pears. Cambridge University Press, Cambridge, pp 268-317

Klein AM, Hendrix SD, Clough Y, Scofield A, Kremen C (2015) Interacting effects of pollination, water and nutrients on fruit tree performance. Plant Biol 17(1):201-208

Klein AM, Vaissiere BE, Cane JH, Steffan-Dewenter I, Cunningham SA, Kremen C, Tscharntke T (2007) Importance of pollinators in changing landscapes for world crops. Proc R Soc B: biological sciences 274(1608):303-313

Maccagnani B, Burgio G, Stanisavljevic LZ, Maini S (2007) Osmia cornuta management in pear orchards. Bull Insectol 60(1):77

Maccagnani B, Ladurner E, Santi F, Burgio G (2003) Osmia cornuta (Hymenoptera, Megachilidae) as a pollinator of pear (Pyrus communis): fruit-and seed-set. Apidologie 34(3):207-216

Marini L, Tamburini G, Petrucco-Toffolo E, Lindström SA, Zanetti F, Mosca G, Bommarco R (2015) Crop management modifies the benefits of insect pollination in oilseed rape. Agric Ecosyst Environ 207:6166

Matson PA, Parton WJ, Power AG, Swift MJ (1997) Agricultural intensification and ecosystem properties. Science 277(5325):504-505

Neilsen D, Hogue EJ, Neilsen GH, Parchomchuk P (1995) Using SPAD-502 values to assess the nitrogen status of apple trees. HortScience 30(3): 508-512
Neilsen GH, Neilsen D, Ferree DC, Warrington IJ (2003) Nutritional requirements of apple. In: Ferree DC, Warrington IJ (eds) Apples: botany, Production and Uses. CABI Publishing, Wallingford, pp 267-302

Neto CB, Carranca C, Clemente J, de Varennes A (2011) Assessing the nitrogen nutritional status of young non-bearing 'rocha'pear trees grown in a mediterranean region by using a chlorophyll meter. J Plant Nutr 34(5):627-639

Porro D, Dorigatti C, Stefanini M, Ceschini A (2001) Use of spad meter in diagnosis of nutritional status in apple and grapevine. Acta Hortic 564: 243-252

Potts SG, Biesmeijer JC, Kremen C, Neumann P, Schweiger O, Kunin WE (2010a) Global pollinator declines: trends, impacts and drivers. Trends Ecol Evol 25(6):345-353

Potts SG, Roberts SP, Dean R, Marris G, Brown MA, Jones R, ... \& Settele $J$ (2010b). Declines of managed honey bees and beekeepers in Europe. J Apic Res, 49(1), 15-22

Ramírez F, Davenport TL (2013) Apple pollination: a review. Sci Hortic 162:188-203

R Core Team (2015) R: a language and environment for statistical computing. R Foundation for statistical computing, Vienna URL https:// www.R-project.org/

Ruel JJ, Ayres MP (1999) Jensen's inequality predicts effects of environmental variation. Trends Ecol Evol 14(9):361-366

Tamburini G, Berti A, Morari F, Marini L (2016) Degradation of soil fertility can cancel pollination benefits in sunflower. Oecologia 180(2): 581-587

Tamburini G, Lami F, Marini L (2017) Pollination benefits are maximized at intermediate nutrient levels. Proc R Soc B Biol Sci 284(1860): 20170729

Tilman D (1999) Global environmental impacts of agricultural expansion: the need for sustainable and efficient practices. Proc Natl Acad Sci 96(11):5995-6000

Vicens N, Bosch J (2000) Pollinating efficacy of Osmia cornuta and Apis mellifera (Hymenoptera: Megachilidae, Apidae) on 'Red Delicious' apple. Environ Entomol 29(2):235-240

Publisher's Note Springer Nature remains neutral with regard to jurisdictional claims in published maps and institutional affiliations. 